\title{
Cultural Computing and the Self Concept: Towards Unconscious Metamorphosis
}

\author{
Tijn Kooijmans ${ }^{1}$ and Matthias Rauterberg ${ }^{2}$ \\ ${ }^{1}$ Studio Sophisti, Amsterdam, The Netherlands \\ ${ }^{2}$ Eindhoven University of Technology, The Netherlands
}

\begin{abstract}
We are exploring an application for a novel direction in humancomputer interaction named 'cultural computing', which aims to provide a new medium for cultural translation and unconscious metamorphosis. The main objective of this project is to create an interactive experience that encourages people in Western culture to reflect on their self-concept. In Western culture the self-concept is generally based on conscious perception of the self. Over centuries the book 'Alice's Adventures in Wonderland' got continuous attention, and therefore seems to be a promising narrative to address issues like logic, rationality, and self. The user in the role of Alice will go through an interactive experience and meets a Caterpillar, who questions the participant's whereabouts of his/her self-concept. To determine the effect of this experience, we discuss a method that measures changes in a person's implicit self-concept for we predict that the experience will have an unconscious effect towards individual metamorphosis. Using the 'implicit association test' (IAT) we could find a significant effect in the hypothesized direction.
\end{abstract}

Keywords: cultural computing, interactive experience, unconscious, selfconcept.

\section{Introduction}

Developments in the field of Human Computer Interaction (HCI) have opened up a new direction for the application of computer technology. After the introduction of personal computing, cooperative computing and social computing, a new paradigm named 'cultural computing' has emerged [22]. Cultural computing is based on what is called Kansei Mediated Interaction [18]. Kansei Mediation is a form of multimedia communication that carries non-verbal, emotional and even unconscious information. "Through the effects of psychology and psychotherapy, the unconscious became an optional ontology through which individuals could reframe their lives. As such, it has become one of the most powerful artefacts of psychology" [26].

First we have to introduce in our understanding and positioning of 'culture'. Westerners and East Asians perceive the world, think about it and act in it in very different ways [21]. Westerners pay primarily attention to some focal object, analyzing its attributes and categorizing it in an effort to find out what determinate its behavior. Determinates used mainly formal logic. Causal attributions tend to focus exclusively on the object and are therefore often mistaken. On the other side, East Asians pay 
primarily attention to a broad perceptual and conceptual field, noticing relationships and changes and grouping objects based on familiarities rather than categories. They relate causal attributions to the context instead of objects. Mainly social factors are directing the East Asians' attention. They live in complex social networks with determined role relations. Attention to the context is more important than to objects for effective functioning.

Westerners live independently in less constraining social worlds and attend to the object and their goals with respect to it. Physical 'affordances' of the environment can also influence perception but is assumed less important. The built environments of the East are more complex and contain more objects than do those of the West. In addition, artistic products of the East emphasize the field and deemphasize objects. In contrast, Western art renders less of the field and emphasizes individual objects and people [21].

The concept 'culture' has been defined and used in many ways throughout different contexts. More than one hundred different definitions for culture can be identified [15]. Anthropologists most commonly use the term culture to refer to the universal human capacity to classify, to codify and to communicate their experiences symbolically [32]. One of the most popular definitions of culture is a complex web of shifting patterns that link people in different locales and that link social formations of different scales. The integration and synchronization of human behavior in a particular cultural system can be achieved on very different time scales, called layers (from years to millennia; see Fig. 1). We do not discuss cultural development on the Y-layer (i.e., individuals, organizations, etc.), C-layer (i.e., societies, nations, etc.), but on the M- or even U-layer (see the concept of archetypes [10]). Over the last several thousands years (the M-layer) the peoples of four distinct regions of the civilized world created the religious and philosophical traditions that have continued to nourish humanity into the present day: (1) Confucianism and Daoism in China; (2) Hinduism and Buddhism in India; (3) monotheism in middle east; and (4) philosophical rationalism in Greece. 'Monotheism' and 'philosophical rationalism' is the religious and cultural foundation of the occident. We will use the term culture as the integration and synchronization of human behavior that includes attitudes, norms, values, beliefs, actions, communications and groups (ethnic, religious, social, etc.).

An important expansion of cultural theories can be discussed as falling into four focal areas [11]: (1) cultures as adaptive systems, (2) cultures as ideational systems, (3) cultures as socio-cultural systems, and (4) cultures as symbolic systems that are cumulative creations of mind. Conceiving culture as an ideational subsystem within a vastly complex system, biological, economical, social and symbolic, and grounding our abstract models and theories in the creation and usage of artifacts should make it possible to deepen the understanding of ourselves and our future. Whether the concept of culture has to be refined, radically reinterpreted, or progressively extinguished will probably not matter in the long run, unless we can not find a way to ask the right strategic questions, identifying connections that would otherwise be unseen, and therefore to enable us finding the best answers for our cultural development. Therefore ambient culture focuses nowadays on the development of open systems that understand and support the rituals of our living and adapt themselves to people through time and space [17]. 

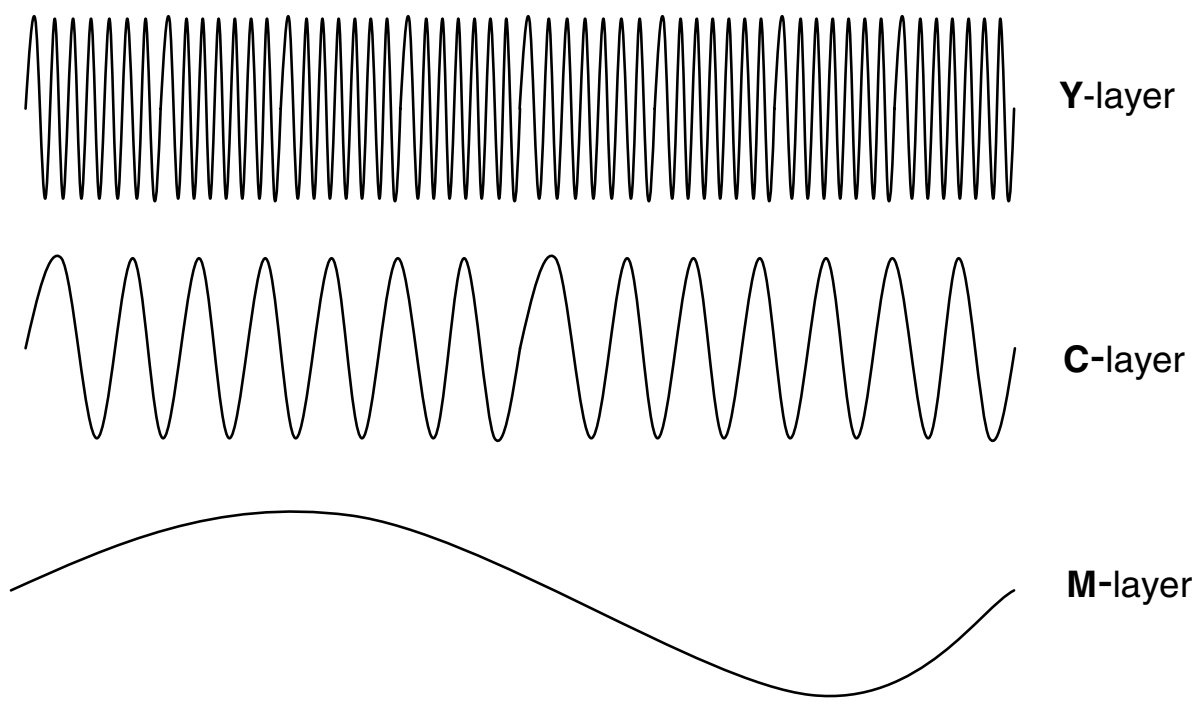

U-layer

Fig. 1. The different layers and time frames for cultural developments ( $\mathrm{Y}=$ year, $\mathrm{C}=$ century, $\mathrm{M}=$ millennium, $\mathrm{U}=$ universal)

Cultural computing is more than integrating cultural aspects into the interaction with computers. It is about allowing the user to experience an interaction that is closely related to the core aspects of his/her culture. In a way that let him/her engage with an augmented reality using the values and attributes of his/her own culture. As such it is important to understand one's cultural determinants and how to render them during the interaction [27]. In this paper we will describe two cultural computing projects, one from the Eastern World (prevailing in Japan) and one from the Western world (prevailing in England). It can be confirmed that Westerners are analytic, paying attention primarily to the object and the categories to which it belongs and using rules, including formal logic, to understand its behavior [20]. In contrast East Asians are more holistic, attending to the entire field and assigning causality to it, making relatively little use of categories and formal logic, and relying on 'dialectical' reasoning. These Western and Eastern types of cognitive processes are embedded in different naive metaphysical systems and tacit epistemologies. It can be speculated that the origin of these differences is traceable to markedly different social systems as part of the underlying cultural determinants [20].

In the Eastern application, cultural computing is defined as cultural translation that uses engineering methods to represent essential aspects of a culture [28] [29]. These engineering methods, such as artificial intelligence and mixed realities can give a person the sense of entering and participating in a different world. 'ZENetic Computer' is such an installation, which incorporates certain elements of the Japanese Zen culture (i.e., sansui paintings, poetry and kimonos). Through an interactive dialog with the system, users can experience the birth of self-awareness brought about 
through the unification of one's everyday self and one's unconscious self [30]. The Zen teachings and symbols that are used in the 'ZENetic Computer' are very typical for the Japanese culture and are not likely to be understood by most people from the West. Therefore the question is how to create a comparable experience in the West that is based on symbols that can touch cultural determinates of Westerners. We tried to answer this question in the project named ALICE by proposing cultural computing based on the story of 'Alice's Adventures in Wonderland' [1] [22] [23] [24]. In the role of Alice, the user goes through an interactive narrative and encounters several stages that are based on selected parts of the original plot. In this paper, we address the stage 'Advice from a Caterpillar', which centers around and focus on the user's self-concept [14]. To support individual metamorphosis and therefore cultural developments by addressing unconscious layers we have to make core concepts of the Western culture consciously available for reflection and disputation. A number of well-known cognitive, emotive and behavioral techniques are available to address our main objectives including disputation of irrational beliefs, emotive techniques and a number of behaviorally oriented assignments [12]. One of the main therapeutic functions of our approach is to support, in all meanings of the term, the symbolic expression of unconscious processes and to try to make these processes intelligible: first of all, intelligible to oneself and then, from the knowledge acquired through one's own experience, to others [16].

\section{The Self}

Throughout history, there have been wide varieties of theories about the self, coming from the fields of philosophy, psychology, and religion. This includes assertions that there is no self; that the idea is a logical, psychological, or grammatical fiction; that the sense of self is properly understood and defined in terms of brain processes; that it is merely a constructed sociological locus, or the centre of personal and public narratives, or that it belongs in an ineffable category on its own [6]. There is a significant difference in the construction of the self when comparing European/American culture and the Japanese culture [13] [21]. Western middle-class cultures are generally organized according to meanings and practices that promote the independence and autonomy of a self that is separate from other similar selves and from social context. This resulted in a prevalent self-esteem among western people with a tendency to selfenhancement. In contrast, many Asian cultures do not highlight the explicit separation of each individual, promoting the fundamental connectedness among individuals in a social group. The result of this on the construction of the self is that they are more likely to engage in self-criticism instead of self-enhancement [13]. Among contemporary researchers in social cognition, distinctions are drawn among self concept (cognitive component), self-esteem (affective component) and self-presentation (behavioral component) [3].

By addressing the Western individual self-concept, Alice's self is challenged in 'Advice from a Caterpillar'. After she entered the rabbit hole to follow the White Rabbit, she experienced a lot of transformations both physically and mentally. This brought her in an initial state of confusion, which is emphasized in her conversation with the Caterpillar: 'Who are YOU?' This challenging attitude of the Caterpillar 
makes Alice uncertain about herself, becoming vulnerable and open for persuasion [5]. Such a situation gives the possibility for a confrontation with and stimulates awareness of the self-concept. The character symbolized as a caterpillar is well chosen. One of the most important characteristic of caterpillars and butterflies is their unique life cycle. One of nature's most mysterious metamorphoses ${ }^{1}$ occurs when a caterpillar changes from a slow-moving, fat and ugly creature to a colorfully winged, beautiful butterfly. This metamorphosis happens to a lot of insects, but not as dramatically as it does to a butterfly [9]. In this respect the 'caterpillar' character can unconsciously pursue the message to a human user not to be afraid of a fundamental metamorphosis in his or her self concept. This symbolic meaning can counterbalances the challenges intended by a conscious dialog next to it.

\section{The Caterpillar Robot}

Using an interactive installation, our goal is to make the participant question her/his own self-concept [14]. Our design strategy is thus to design the installation in such a way that the participant's experience is as consistent as possible with Alice's experience in the original story. Caused by the preliminary stages in the ALICE installation, the user will feel small and therefore confused about what happened (criteria 1 ). We also expect s/he wants to know what this entire means (criteria 2). Criteria (1) and (2) correspond with guidelines for timing persuasion [5]. Hence, it creates an opportune moment to question whether people are, and what they think they are. On entering the stage, the user will meet a Caterpillar, who has its back turned towards the user. He is humming softly and smoking a water pipe. When the user comes closer and enters the personal space of the Caterpillar, he suddenly wakes up, turns and bends towards the user. This should be a spontaneous movement to yield a surprise reaction. 'Who are YOU?' the Caterpillar asks first. This should initiate a dialog in which the Caterpillar is leading. During the dialog, the Caterpillar maintains eye contact with the user and supports its utterances with subtle body expressions. The question 'You? Who are YOU?' is repeated whenever the participant speaks with the words 'I', 'my', 'me' or 'mine' until s/he replies with a sentence like 'I don't know'. This will initiate a monologue of the Caterpillar about the transience of the self and his future metamorphosis into a beautiful butterfly. After that, he sends the user away.

\subsection{Form and Movement}

In order to make the Caterpillar prototype work as an unconscious symbol of metamorphosis, it is important that the form of the prototype matches with the archetypical form of a caterpillar. In moving from a natural form of a caterpillar towards an embodied artificial representation (further called 'robot'), there were several considerations taken into account. First of all, it demands for social abilities in order to become a persuasive character [5]. Since people have a basic tendency to project human beings onto animistic objects [25], there is no need for really adding a human face onto the robot to make it social [2]. We equipped our robot with only one eye and a mouth, to enable gaze and talk. Another aspect in achieving social abilities is lifelike behavior

\footnotetext{
${ }^{1}$ The Greek word 'metamorphosis' means 'change in form'.
} 
[31]. We implemented this by means of a periodical wave motion of the robot's body that resembles the locomotive contractions and extractions of a real Caterpillar. Furthermore, the robot gazes at its dialog partner by aiming its body, eye and head. This gaze was implemented semi-contingent, which means that it combines random movements with reactive movements. A contingency factor of $60 \%$ (40\% random, $60 \%$ reactive) will be perceived as most lifelike for communication robots [31].

To enable these required movements, we have equipped our robot with a number of servomotors that provide in total nine degrees of freedom. Four degrees of freedom are dedicated to the periodic motion of its body, two for horizontal and vertical rotation of its head, two for horizontal and vertical rotation of its eye, and one for the overall rotation of the body. To determine the position and distance of the participant, the robot has an array of nine motion detection sensors around its base and a rotating distance sensor. A limitation of this configuration is that it is impossible to measure the vertical size of a participant for proper gazing.

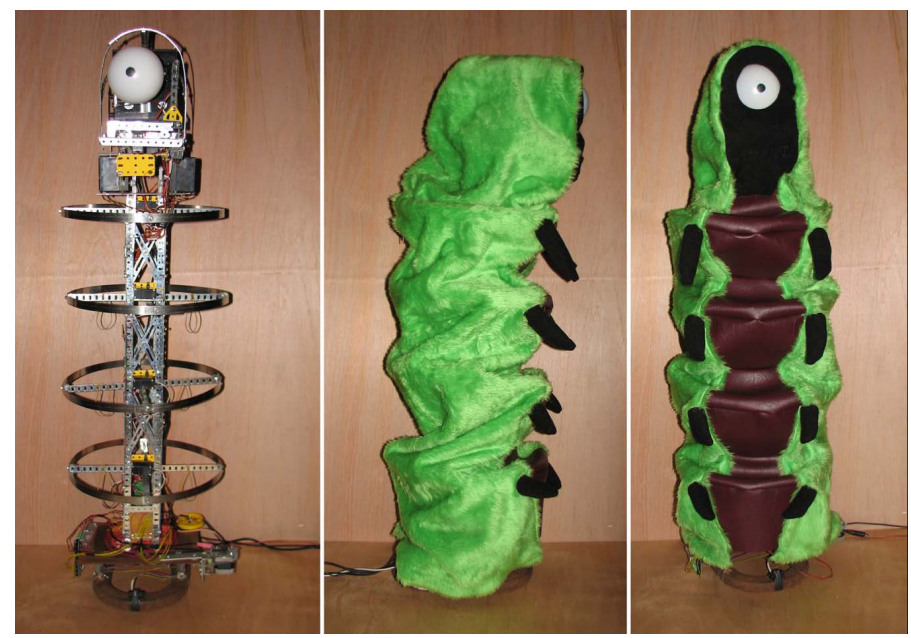

Fig. 2. The appearance of the caterpillar robot (skeleton,, side, front)

\subsection{Dialog Management}

Since the dialog between the Caterpillar and the participant is one of the crucial components of the interaction, we will address this in more detail. In order to engage the participant in a spoken dialog with the Caterpillar, there is a need for a system that facilitates speech input to understand the participant, speech output to talk to the participant and script control to steer the dialog in the right direction. The problem here is that every person will react differently to what the Caterpillar says; hence the dialog cannot be fully pre-programmed and should be constructed dynamically, we will outline the implemented technologies that deal with this. In choosing between a synthetic or recorded voice, it should be well taken into account that if a robot has a recorded (read: naturally human) voice, people feel easily tricked when the robot doesn't look human [19]. This argument made us choose for a synthetic voice for the 
Caterpillar robot. A drawback of this decision is that it became difficult to give emotional expression or emphasis to utterances. In line with the earlier mentioned guidelines for persuasion, we have selected a voice that resembles a wise person. To pursue consistency with the original story, it is a male and bit languid, sleepy voice.

For speech input, the available technology is speech recognition. The current status of natural language recognition through speech is still of low quality and needs training time to let the system get used to a voice. To overcome this problem we have used a limited set of vocabulary to detect. When focusing only on a small set of key words, the accuracy of speech recognition can increase significantly. An advantage is that the Caterpillar steers the dialog and act as an agent. It can then predict the possible answers a participant is likely to give. To control the dialog, we implemented a scriptbased dialog management system. Input sentences are analyzed on the basis of decomposition rules, which are triggered by key words appearing in the input text. Responses are generated by reassembly rules associated with selected decomposition rules. The rules are stored in a script and can be edited to tailor the software for a specific application.

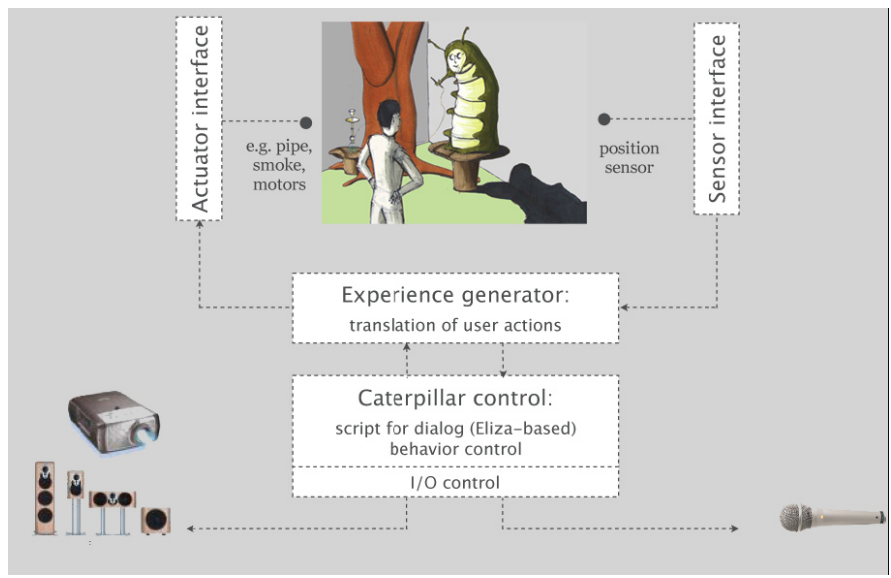

Fig. 3. System architecture and overall structure

Fig. 3 gives a global overview of the software framework of our prototype. The dashed-line boxes contain the following software components for the system:

- The main component is the experience generator. This takes care of the overall management of the installation and schedules the execution and transitions of the different states of the interaction script.

- The next component is in charge of the Caterpillar control, which manages the behaviors of the robot. It also incorporates a dialog manager that steers the conversation with the participant according to the predefined script, and deals with the speech input and output of the robot.

- The role of the sensor interface is to gather information about the participant in the installation. This is done by translating the retrieved data from the distance and mo- 
tion sensors into higher-level information, such as the position of the participant in the area around the robot.

- The actuator interface controls the hardware part of the installation, which basically consists of the robot's motors. The actuators are activated through the experience generator and Caterpillar control components.

\section{Experience Assessment}

To measure the effect of our installation with respect to our objective, we need to test whether users experience any changes in self-concept when coming out of the test. We hypothesize that our installation will have mainly an unconscious effect on the self concept of our test subjects. We have to distinguish between conscious (explicit) and unconscious (implicit) cognition and the way they influence human responses [7]. The Implicit Association Test (IAT) focuses only on the implicit (unconscious) part of cognition [7] [8]. The IAT measures differential (unconscious) association of two target concepts with an attribute. The two concepts appear in a binary choice task (e.g., flower vs. insect names), and the attribute in a second task (e.g., pleasant vs. unpleasant words for an evaluation attribute). When instructions oblige highly associated categories (e.g., flower + pleasant) to share a response key, performance is faster than when less associated categories (e.g., insect + pleasant) share a key. This performance difference implicitly measures differential association of the two concepts with the attribute. We used the IAT version that especially measures self-concept [8]. This is a useful measure for the experience assessment of our test subjects.

We have conducted an experiment, which can measure any significant difference between a subject's self-concept before and after going through the installation and having interaction with the Caterpillar. 18 university students took part in this experiment ( 3 from art, 5 from medicine, 10 from industrial design; age 19-25; both genders). We used a modifiable flash-based implementation of the IAT [33]. The procedure of our experiment was as follows: (1) Subject fills in self-concept IAT (before). (2) Participant enters the installation room and interacts with the Caterpillar based on the interaction script (3-8 min). (3) Subject fills in self-concept IAT (after).

Table 1. Result of the MANOVA for the repeated measures of the IAT

\begin{tabular}{lll}
\hline Measure & Mean $(\mathrm{std})$ & \\
\hline IAT before & $43.4( \pm 24.5)$ & $\mathrm{N}=18$ \\
IAT after & $21.3( \pm 24.1)$ & $\mathrm{N}=18$ \\
Main effect & $\mathrm{Df}=1, \mathrm{~F}=13.4, \mathrm{MS}=4399.3$ & $\mathrm{P} \leq 0.002$ \\
\hline
\end{tabular}

The results of these 18 test-subjects were gathered and analyzed using withinsubject MANOVA (SPSS Vers. 12.01 for Windows). The average score of test A, on a scale of 0 to 100 , significantly decreased from 43 to 21 ( $\mathrm{P} \leq 0.002$, see Table 1$)$. This indicates that the measured unconscious self-concept changed significantly before and after the test in line with our hypothesis. Our test subject becomes less self confident and more separated from their original self concept. This can help to change the selfconcept of Westerners to less individualism and egoism. If we assume that association 
strengths measured by the IAT are often not accessible to conscious inspection, then the difference between self-reports and IAT can be understood as a difference in their access to unconscious knowledge. Our experiment set out developing a theoretical integration of the important cognitive construct (self-concept) with its most important affective construct (self-esteem) to start investigating effects based on cultural computing.

An important limitation that one should take into account when assessing the individual experience of 'Advice form a Caterpillar' only, is that in the original story, there are a number of experiences such as 'falling down the rabbit hole' and 'shrinking and growing' that precede this encounter with the caterpillar. This could have a limiting or even enhancing effect on the unconscious impact of the experience. In addition, our experiment did not have a proper control group, so we can not claim any causal relationship. We are therefore looking forward to reassess the experience with the full installation in a later stadium of the ALICE project [34].

\section{Conclusions}

We have introduced and discussed an application for the new field named cultural computing, based on one particular part in the narrative 'Alice in Wonderland' [1]. This narrative addresses the individual self-concept of Westerners through an interactive experience of Alice's encounter with a caterpillar. Our installation can offer an experience that is similar and consistent with the original narrative. The encounter with our caterpillar robot had a significant influence on the self-concept of our test subjects in such a way, that these users get less attached to their self-concept. This can be seen as valuable contribution to cultural computing by providing access to the unconscious determinates of the Western culture: the self-concept as an individual. This can change Westerners to weaken their self-concept to become less individualistic and egoistic for the benefit of future societies [4].

Acknowledgments. This project is sponsored by Microsoft Research in Cambridge, UK. We want to thank D. van de Mortel, J. Hu, C. Seyfert, and J. Goldstein for their valuable contributions to our project.

\section{References}

[1] Carroll, L.: Alice's adventures in Wonderland. Macmillan, London (1865)

[2] Bartneck, C.: Negotiating with an embodied emotional character. In: Forzlizzi, J., Hamington, B., Jordan, P.W. (eds.) Design for Pleasurable Products, pp. 55-60. ACM Press, Pittsburgh (2003)

[3] Brehm, S.S., Kassin, M.S., Fein, S.: Social psychology, 4th edn. Houghton Mifflin, Boston (1999)

[4] Deikman, A.J.: The observing self: mysticism and psychotherapy. Beacon Press (1983)

[5] Fogg, B.J.: Persuasive technology, using computers to change what we think and do. Morgan Kaufmann Publishers, San Francisco (2003)

[6] Gallagher, S., Shear, J. (eds.): Models of the self. Imprint Academic, Exeter (1999) 
[7] Greenwald, A.G., McGhee, D.E., Schwartz, J.K.L.: Measuring individual differences in implicit cognition: The Implicit Association Test. Journal of Personality and Social Psychology 74(6), 1464-1480 (1998)

[8] Greenwald, A.G., Farnham, S.D.: Using the Implicit Association Test to measure selfesteem and self-concept. Journal of Personality and Social Psychology 79(6), 1022-1038 (2000)

[9] Heiligman, D.: From caterpillar to butterfly. A Let's-Read-and-Find-Out Science Book (1996)

[10] Jung, C.G.: Man and his Symbols. Doubleday Garden City, New York (1969)

[11] Keesing, R.M.: Theories of culture. Annual Review of Anthropology 3, 73-97 (1974)

[12] Kinney, A.: The intellectual-insight problem: implications for assessment and RationalEmotive Behavior Therapy. Journal of Contemporary Psychotherapy 30(3), 261-272 (2000)

[13] Kitayama, S., Markus, H.R., Matsumoto, H., Norasakkunkit, V.: Individual and collective processes in the construction of the self: self-enhancement in the United States and selfcriticism in Japan. Journal of Personality and Social Psychology 72(6), 1245-1267 (1997)

[14] Kooijmans, T., Rauterberg, M.: Advice from a caterpillar: an application for cultural computing about the self. In: Harper, R., Rauterberg, M., Combetto, M. (eds.) ICEC 2006. LNCS, vol. 4161, pp. 5-8. Springer, Heidelberg (2006)

[15] Kroeber, A.L., Kluckhohn, C.: Culture: A critical review of concepts and definitions. Peabody Museum, Cambridge, Massachusetts (1952)

[16] Leclerc, J.: The unconscious as paradox: impact on the epistemological stance of the art psychotherapist. The Arts in Psychotherapy 33, 130-134 (2006)

[17] Marzano, S.: Ambient culture. In: Aarts, E., Encarnação, J. (eds.) True visions- the emergence of ambient intelligence, pp. 35-52. Springer, Heidelberg (2006)

[18] Nakatsu, R., Rauterberg, M., Salem, B.: Forms and theories of communication: from multimedia to Kansei mediation. Multimedia Systems 11(3), 304-312 (2006)

[19] Nass, C., Brave, S.: Wired for Speech: How voice activates and advances the humancomputer relationship. MIT Press, Cambridge (2005)

[20] Nisbett, R.E., Peng, K., Choi, I., Norenzayan, A.: Culture and systems of thought: Holistic versus analytic cognition. Psychological Review 108(2), 291-310 (2001)

[21] Nisbett, R.E., Masuda, T.: Culture and point of view. PNAS 100(19), 11163-11170 (2003)

[22] Rauterberg, M.: From personal to cultural computing: how to assess a cultural experience. In: Kempter, G., von Hellberg, P. (eds.) uDayIV-Information nutzbar machen, pp. 13-21. Pabst Science Publisher, Lengerich (2006)

[23] Rauterberg, M.: Usability in the future -explicit and implicit effects in cultural computing. In: Heinecke, A.M., Paul, H. (eds.) Mensch \& Computer 2006: Mensch und Computer im StrukturWandel, pp. 29-36. Oldenbourg Verlag, München (2006)

[24] Rauterberg, M.: How to assess the user's experience in cultural computing. In: Bosenick, T., Hassenzahl, M., Müller-Prove, M., Peissner, M. (eds.) Usability Professionals 2006, Fraunhofer Informationszentrum Raum und Bau, pp. 12-17 (2006)

[25] Reeves, B., Nass, C.: The Media Equation: How people treat computers, television, and new media like real people and places. Cambridge University Press, New York (1996)

[26] Shamdasani, S.: Unconscious. In: Odijk, E., Syre, J.-C., Rem, M. (eds.) PARLE 1989. LNCS, vol. 365, p. 1921. Springer, Heidelberg (1989)

[27] Tosa, N., Nakatsu, R.: Interactive Comedy: Laughter as the next intelligence system. In: Proceedings International Symposium on Micromechatronics and Human Science, pp. 135-138. IEEE Computer Society Press, Los Alamitos (2002) 
[28] Tosa, N.: Interactive Comedy. Journal of the Institute of Image Information and Television Engineers 57(4), 454-455 (2003)

[29] Tosa, N., Matsuoka, S.: Cultural computing: ZENetic computer. In: ICAT'04. Proceedings of the 14th International Conference on Artificial Reality and Tele-existence, pp. 7578, Korea Advanced Institute of Science and Technology, Korea (2004)

[30] Tosa, N., Matsuoka, S.: ZENetic Computer: Exploring Japanese Culture. Leonardo 39(3), 205-211 (2006)

[31] Yamaoka, F., Kanda, T., Ishiguro, H., Hagita, N.: Lifelike behavior of communication robots based on developmental psychology findings. In: Proceedings IEEE International Conference on Humanoid Robots, pp. 406-411. IEEE Computer Society Press, Los Alamitos (2005)

[32] Retrieved on (March 23, 2007) from http://en.wikipedia.org/wiki/Culture

[33] Test of Unconscious Identification (TUI):

http://jamiep.org/mod/tui/view.php?id=154\&do=test

[34] The ALICE project: http://www.alice.id.tue.nl/ 